\title{
Grounding Abstract Concepts in Action
}

\author{
Semantic Analysis of Four Italian Action Verbs \\ Encoding Force Events
}

\author{
Paola Vernillo
}

\section{Introduction}

Over the past recent years, different works connected over the idea that language, cognition, and bodily experience must be considered as inextricably intertwined areas of research (Gallese and Lakoff 2005; Lakoff and Johnson 1999). A consistent number of multidisciplinary studies showed that sensory-motor information influences our cognitive structures and thus represents a primary source in the operation of meaning construction (amongst others, Martin and Chao 2001; Pulvermüller 2005).

In this large frame, action verbs play a pivotal role. They are recognized as primary tools both in the linguistic encoding of bodily knowledge and in the linguistic representation and modeling of a wide array of highly abstract concepts (Panunzi and Vernillo 2019). Action verbs are mainly used to encode very different types of action events and bodily schemas. Their semantic extension allows us to refer to a myriad of experiences, affordances, bodily movements, and relations between physical objects (i.e., primary variation). Moreover, these predicates are pervasively used to encode a large and complex array of abstract concepts and figurative meanings (i.e., marked variation), for whose labeling they coherently re-use their rich action imagery. The class of action verbs represents a case of exceptional interest within the verb lexicon category. These verbs are not only among the primary words of children's vocabulary (Tomasello 2003) but they are also among the most common tools in oral communication, having an even more significant weight than nouns in spoken language use

Electronic supplementary material The online version of this chapter (https://doi.org/10.1007/978-3-030-69823-2_8) contains supplementary material, which is available to authorized users.

P. Vernillo (凶)

Università degli Studi di Firenze (UNIFI), Firenze, Italy

e-mail: paola.vernillo@unifi.it 
(Gagliardi 2014; Moneglia 2014a, b). Moreover, and differently from other predicates, action verbs directly anchor, on the level of language, the domain of sensorymotor experience to that of highly abstract thought. Therefore, the analysis of these predicates' semantic variation may ease the understanding of how spatial and bodily information (spatial vectors, motion patterns, force dynamics) is mapped to make new and non-literal meanings emerge.

This work, ${ }^{1}$ whose primary research field is that represented by Cognitive Linguistics and Semantic Theory, starts from the hypothesis that there exists a sort of hidden relation between the two dimensions of use and meaning of a given action verb (i.e., primary and marked variation); and that it there also exists a sort of correspondence between the type of action and metaphorical concepts which can be expressed by means of the same predicate. The main research questions this study has been built upon can be spelled out as it follows:

1. What are the relationships between the concrete (i.e., primary variation) and the metaphorical (i.e., marked variation) uses of a given action verb?

2. Which semantic features of the action verb determine the metaphorical potential of the verb? And how do we determine which action verb can allow us to access which metaphorical concept or figurative meaning?

3. Finally, how can we explain divergent metaphorical potentials of action verbs involved in the encoding of the same type of action events (i.e., locally equivalent verbs)?

It is worth to bear in mind that these questions are not only relevant with respect to my research field (i.e., Linguistics), but are closely connected to the three main research questions this volume starts from (Bechberger and Liu, this volume):

a. On the representation level: how can we formally describe and model concepts (Färber, Svetashova, and Harth, this volume; Gust and Umbach, this volume)? And, more specifically, how do we use characteristics of action concepts to formally model more abstract ones?

b. On the learning level: where do concepts come from and how are they acquired (Bechberger and Kühnberger, this volume)? And, in particular, how do we transfer sensory-motor information to new and more abstract contexts?

c. On the application level: how are concepts used in cognitive tasks (Gega, Liu and Bechberger, this volume; Scerrati, Iani, and Rubichi, this volume; Schneider and Nürnberger, this volume)? And, with respect to the present research, how do we apply our action-knowledge in linguistic contexts where no physical action is implied?

To give all these questions an answer, in this study, I aim at investigating the semantic variation of a small group of Italian action verbs (ita., premere, spingere, tirare and trascinare; Eng., to press, to push, to pull, and to drag) involved in the encoding of the force-dynamics category (Langacker 1987). Although the four verbs

\footnotetext{
${ }^{1}$ This research partially bases on two previous works (Panunzi and Vernillo 2019; Vernillo 2019) and on the author's doctoral dissertation (Vernillo 2020, unpublished).
} 
in analysis belong to the same semantic class (i.e., force), they profile different types of action concepts and events. It seems reasonable to believe that the specific imageschematic features associated with their action imagery influence the differences in their semantic extension and linguistic use. Nevertheless, along the semantic axis (i.e., primary and marked variation), there also exist specific points where the uses of these verbs tend to converge. For instance, happens that, in some specific pragmatic contexts, the uses of premere converge with those of spingere (e.g., setting relationships between objects), or the uses of trascinare converge with those of tirare (e.g., the frictional motion of an object along a surface). These verbs show a partial convergence (or divergence) not only with respect to their primary variation (i.e., when encoding physical concrete meanings), but also with respect to their marked variation (i.e., when encoding figurative meanings). For example, there are cases in which the verb premere (Eng., to press) and the verb spingere (Eng., to push) refer to the same type of metaphorical concept (e.g., PSYCHOLOGICAL FORCES ARE PHYSICAL FORCES), or cases in which the verb tirare (Eng., to pull) and trascinare (Eng., to drag) encode the same type of conceptual metaphor (e.g., CAUSES ARE FORCES AFFECTING MOTION).

The present study bases on the idea that a deep analysis of the action imagery associated to these predicates can help us to shed new light on their behavior in metaphorical contexts. To support this idea, in the following paragraphs, I will describe the semantic variation of each of the four verbs, mainly focusing on the salient image-schematic structures and the specific action schemas that characterize the primary core of the verbs. Additionally, I will explain how these same structures and schemas permit to bond together the marked (i.e., largely metaphorical) and the primary variation of the verbs (Lakoff 1990, 1993; Turner 1991). In Sect. 2, I will present the ontological infrastructure within which my analysis was developed with. In Sect. 3, I will give a general overview of the theoretical approaches (i.e., Conceptual Metaphor Theory, Image Schema Theory, and Embodiment) that mainly influenced my approach to the analysis of action verbs. In Sect. 4, I will present the collection of data and the methodology I used for these predicates' annotation. Section 5 will describe the primary variation of each of the four verbs, and it will be mainly focused on the salient image-schematic structure and the specific action schemas that characterize the primary core of the verbs. In Sect. 6, I will illustrate the marked variation of the predicates, and I will explain how the same structures and schemas highlighted in the primary variation of the four verbs permit the bonding of the marked (or largely metaphorical) and the primary variation of the verbs (see the Invariance principle: Lakoff 1990, 1993; Turner 1991). In Sect. 7, I will briefly discuss the results obtained by comparing primary and marked variation of the four predicates in the analysis. First, I will show that the results of the study are consistent with the idea that metaphorical extensions of action verbs are constrained by the image-schematic structures involved in the core meaning of the verbs. Second, I will point out that these same structures are also responsible for the divergencies found within the metaphorical variation of action verbs pertaining to the same semantic class (i.e., force). Finally, in Sect. 8, I will draw some general conclusions about the type of study that I proposed. 
Table 1 Visual representation of action concepts in IMAGACT

\begin{tabular}{l|l|l|l|l}
\hline Action type & Scene & Standardization & Verb & LEV \\
\hline $\begin{array}{l}\text { Setting relations } \\
\text { between two } \\
\text { objects }\end{array}$ & & $\begin{array}{l}\text { Marta preme il } \\
\text { coperchio sulla } \\
\text { scatola } \\
\text { (Eng., Mary } \\
\text { presses the lid } \\
\text { onto the box) }\end{array}$ & $\begin{array}{l}\text { Premere } \\
\text { (Eng., to press) }\end{array}$ & $\begin{array}{l}\text { Spingere } \\
\text { (Eng., to push) }\end{array}$ \\
\hline
\end{tabular}

\section{The Semantic Representation of Action Verbs in the IMAGACT Ontology}

The semantic characterization of action verbs given in this study owes a great deal to the representation of action events and concepts the IMAGACT Ontology was built upon. This is why, the following paragraphs will be devoted to the general description of the Ontology (Sect. 2.1), and the definition of the notion of primary (Sect. 2.2) and marked variation (Sect. 2.3).

\subsection{The Internal Structure of the IMAGACT Ontology}

IMAGACT is a multimodal and multilingual ontology that depicts action via a visual representation system. The choice to represent action concepts by using both prototypical 3D animations and brief videos (Moneglia 2014a, b; Panunzi et al. 2014) stemmed from two needs: first, to avoid the vagueness of semantic definitions, and second, to have a resource that could have disentangled action categorization from a specific language representation (Brown 2014).

IMAGACT includes more than 1000 distinct action scenes that have been primarily derived from the annotation of spoken language corpora in English and Italian. While in a preliminary phase of the project, Chinese and Spanish data were also processed, extensions to (Syrian) Arabic, Danish, German, Hindi, Japanese, Polish, Portuguese, and Serbian were made available on the online interface ${ }^{2}$ only recently.

The visual representation of the action concepts is organized as the following: each prototypical scene is linked to a single action concept (or action type), each action verb is connected to more than one prototypical scene, and each prototypical scene is associated to more than one action verb. Some action verbs share a common referent (or a subset of action scenes) and are hence called locally equivalent verbs (e.g., to push and to press). The following Table 1 gives a brief schematization.

Concerning the present analysis, the IMAGACT framework represents an important point of reference for the investigation of action verbs semantics. First, the

\footnotetext{
${ }^{2} \mathrm{https}: / /$ www.imagact.it/imagact/query/dictionary.seam.
} 
Ontology contains a consistent amount of data that has been massively taken from multiple spoken resources (e.g., IMAGACT and BNC corpora). Second, this resource provides a well-structured visual categorization of action concepts and of bodily schemas encoded by general action verbs which are most used in everyday language. Third, it permits to hook the linguistic representation of the highly abstract concepts (and of the figurative meanings) encoded by a given action verb to the very inherent semantic core of the verb. Finally, it eases the interpretation of the variation axes of the predicate (i.e., primary and marked variation), since they are jointly considered rather than entirely separate dimensions of the lexical item. The rich semantic information included in the database helped to better structure the annotation of the metaphorical uses of the action predicates. Moreover, it helped to expand the number of details that have been used to show that either metaphorical and physical uses of action verbs are not randomly produced, but that they both refer to crucial motor and perceptual inputs coming from our cognitive and actual representation of actions.

\subsection{The Primary Variation of Action Verbs}

Within the IMAGACT Ontology, the semantics of action is described as based two main axes of variation: the primary and the marked variation. Importantly, the resource keeps the verb occurrences of the two types of variation well distinct. The procedure via which metaphorical and phraseological usages are separated from those strictly referring to physical actions is made possible through the adoption of an operational test à la Wittgenstein (Gagliardi 2014). According to this test, the verb uses are judged primary if it is possible to point to a certain (perceptible) event and says to someone who does not know the meaning of a given verb that "this action and similar events are what we refer to with this verb"; contrarily, the occurrences that do not instantiate the basic meaning of the verb are tagged as marked.

Within the ontology, the expression primary variation refers to the set of different action types to which a given action verb can refer in its proper sense (or concrete physical meaning). To illustrate this point, some of the possible physical uses of the Italian action verb spingere (e.g., to push) are considered:

(1) "Marta spinge il pulsante"

"Marta pushes the button"

(2) "Marta spinge il coperchio sulla scatola"

"Marta pushes the lid onto the box"

"Marta spinge il carrello lungo il corridoio"

"Marta pushes the cart down the hall"

"La nuotatrice si spinge con le gambe"

"The swimmer pushes herself off of the wall with her legs"

All the listed examples (1-4) are recognized as instantiations of the primary meaning of the verb spingere (Eng., to push). The semantics of the predicate is shown in all 
its complexity while encoding different linguistic and cognitive traits. In examples (1-2), the verb can be substituted by the same locally equivalent verb (e.g., premere), even though the scenes refer to two action types: in the former case, the verb describes the application of force on an object to activate a connected device; in the latter case, the verb describes a situation in which a human agent applies a force to set a relation between two entities. In examples (3-4), the verb spingere cannot be substituted by the same locally equivalent verb: the meaning of case (3) cannot be encoded by another predicate. The event in case (4) cannot be named by a single verb but only by a more complex syntactic structure, such as 'darsi una spinta' (Eng., 'to give yourself a push'). Moreover, the examples in (3-4) describe two types of motion event in the physical space. In (3), the verb names an event in which a human agent causes an object to move along a path (caused motion). In example (4), the verb encodes an event in which a human entity moves spontaneously along a path without the intervention of an external force (self-propelled motion).

\subsection{The Representation of the Marked Variation of Action Verbs}

The term marked variation refers to the set of uses in which the action verb does not encode physical concepts but abstract/figurative (Moneglia et al. 2012; Panunzi and Moneglia 2004). Let us consider the following four sentences, which partially exemplify the variation of the verb spingere (e.g., to push):

$$
\begin{aligned}
& \text { "L'oratore spinge sui temi sociali" } \\
& \text { "The speaker is pressing on the social agenda" } \\
& \text { "La situazione spinge il Consiglio a intervenire" } \\
& \text { "The situation is pushing the Council to intervene" } \\
& \text { "L'autore ama spingere i suoi personaggi" } \\
& \text { "The author likes to push his characters" } \\
& \text { "La situazione si spinge verso l'anno successivo" } \\
& \text { "The situation will extend onto the next year" }
\end{aligned}
$$

The sentences in (5-8) do not instantiate the basic meaning of the verb spingere (Eng., to push). These examples are based on different semantic processes (mostly metaphorical). Thereby the verb undergoes a semantic shift; it has thus been used to express different kinds of metaphorical meanings. In particular, the predicate represents a situation in which a speaker conveys a specific communicative intention (5), implies an act of psychological influence (6), defines the artistic manipulation put in place by an author (7), or names the time extension in the duration of an event (8).

As stated above, marked uses are sharply separated from the occurrences referring to concrete physical actions and annotated in a different online interface. Unfortunately, although an ad-hoc infrastructure was designed to classify the marked uses 
found in the variation of the action verbs (Brown 2014), the IMAGACT ontology only specifies the semantic interpretations of predicates with respect to their physical actions: hence, other kinds of interpretations are ignored and are not visually represented. The lack of a clear depiction of marked uses is not connected in any way to their semantic load within the infrastructure (they represent half of the IMAGACT database occurrences). This problem must be rather explained by reference to the visual format of the ontology, which makes it not easy to represent abstract concepts (Brown 2014).

\section{Body, Metaphors, and Metaphorical Projections of Image Schemas}

The analysis focuses on two essential aspects: first, the action verbs semantics and, second, the particular role played by action bodily information. In the following paragraphs, I will give a brief overview of the main theoretical scenarios my analysis has been developed with. Before going through a proper analysis of the semantic variation of action verbs, three fundamental frameworks need to be illustrated: in Sect. 3.1, I will present the main tenets underpinning the embodied theory of language. In Sect. 3.2, I will introduce the key points behind Lakoff and Johnson's Conceptual Metaphor Theory. In the final Sect. 3.3, I will focus on the Image schemas Theory, as well as its role within a deep level language analysis.

\subsection{The Embodied Paradigm}

Recently, interest has grown in the idea that language and cognition should be investigated with respect to the deep relationship to bodily experience (Aziz-Zadeh and Damasio 2008; Desai et al. 2011; Gallese and Lakoff 2005; Kiefer and Pulvermüller 2011; Martin and Chao 2001; Pulvermüller 2005). Embodied cognition theories are based on the assumption that between the level of cognitive processes (action and perception) and abilities (abstract thought and language comprehension) there is no defined boundary or sharp separation (Zipoli Caiani 2011). Accepting that not only the brain but also features of the agent's body play a significant role in cognitive processing means to embrace the idea that our entire conceptual system is largely constrained by the kind of body and sensory-motor processes we are characterized by as humans. The body emerges as a crucial locus and represents a functional restraint that imposes its structure on different domains of human experience (Zipoli Caiani 2011). But what does it mean to embrace the embodied paradigm when it comes to language? The embodied approaches emerged in response to the cartesian (or cognitivist) paradigm. According to this paradigm, the brain is viewed as a processor 
of abstract information, while cognition should be defined as the computation of abstract symbols that the language is made of (Varela 1991).

Contrarily, embodied theories (Barsalou 2008, 2016; Johnson 1987; Lakoff 1987; Lakoff and Johnson 1980, 1999; Wilson 2002) argue that reasoning, concepts, and language are grounded in experience and tightly bonded to the body and its specific features. In this framework, it is claimed that the body and its inherent way of functioning and interacting in the physical space, directly impinge on our cognitive structures, and it thus represents one of the primary sources in the operation of meaning construction (Lakoff and Johnson 1999). A consistent number of empirical studies indeed showed that conceptual knowledge is deeply rooted in perceptual and motor systems (Gallese and Lakoff 2005; Martin and Chao 2001; Pulvermüller 2005). Additionally, it was shown that sensory-motor simulations directly impinge on the processing and understanding of language (Glenberg and Kaschak 2002; Tettamanti 2005).

The adoption of an embodied approach to the study of lexicon relies on the idea that bodily properties have a crucial function in meaning construction processes. Embodied theories, in fact, directly look at body and language as a tight coupling, in which the comprehension of the latter cannot take place without information deriving from the former (Gibbs and Colston 1995; Gibbs 2005). As I will show, bodily features, sensory inputs, and action-oriented schemas do also play a pivotal role in the construction and extension of the action verbs' meaning, both on the concrete and the abstract representation level (Panunzi and Vernillo 2019). This is why, in this paper, not only physical but also figurative meanings of action verbs have been accounted for by working on the idea that sensory-motor processes can provide us with more data on human understanding and representation of concrete and abstract concepts. The starting point of the analysis will be that the different semantic layers (i.e., primary and marked variation) characterizing the semantic core of action verbs should not be viewed as separate dimensions of the lexical meaning but, rather, as deeply and strongly connected.

\subsection{Conceptual Metaphor Theory}

The Conceptual metaphor theory (henceforth CMT: Lakoff and Johnson 1980, 1999) represents one of the most powerful theories on abstract reasoning. Over the years, CMT has benefited from a consistent number of empirical researches which guaranteed, in some way, the reliability of the approach (Casasanto and Bottini 2014; Gibbs 2006; Jamrozik et al. 2016). One of the essential claims of CMT is that metaphors concern not only the way we use language but also the way we organize human thought. In this theoretical scenario, metaphors are not conceived as mere rhetoric tropes but rather as cognitive processes, by means of which aspects of human cognition, perception, and experience are transposed in language (Lakoff and Johnson 1980). CMT can be considered as the most embodied approach to the study of language. It is in fact based on the idea that the way we refer to abstract 
concepts exploits the rich flow of information which we gain from our experience of the world and of the way we bodily interact with the world and the objects therein. According to Lakoff and Johnson (1980: 115), a large number of concepts that are meaningful to us are either abstract or not well delineated in our experience. They thus necessitate being conceived via concrete concepts that we can understand in clearer terms. The internal structure of many abstract concepts, such as Changes, States or Causes, appears to be cognitively grounded in the metaphorical mapping of more concrete schemas as, say, FORCE and MOTION (Gibbs 2006; Lakoff and Johnson 1980, 1999). People talk about state changes in the same way they talk about motion changes (e.g., CHANGE OF STATE IS CHANGE OF MOTION), causes in the same way as forces (e.g., CAUSES ARE FORCES), or states as physical locations in the space (e.g., STATES ARE LOCATIONS).

Metaphors are based on a conceptual mapping operation that transfers preconceptual knowledge from one concrete source domain to an abstract target domain (Lakoff and Johnson 1980). The information transfer must respect some basic rules and is supposed to be constrained by a number of different factors that can enable or stop the metaphorization process (Brygida Rudzka-Ostyn 1995). Amongst others, it is worth noticing that the mapping is not an exhaustive process, that is, not all but just some aspects of the source domain are transferred onto the target domain (see partial metaphorical utilization phenomenon in Kövecses 2010). The mapping is conditioned by an asymmetrical directionality, according to which the transfer may only go from the source to the target domain and not vice-versa (Lakoff and Johnson 1980). Moreover, the mapping operation must not violate the internal structure of the target domain (i.e., target domain override). According to the Invariance Principle Hypothesis (Lakoff and Turner 1989; Lakoff 1990, 1993; Turner 1991), the metaphorical mapping must preserve the cognitive topology (or image-schematic structure) of the source domain consistently with the inherent structure of the target domain.

As the present work is concerned with the analysis of the semantic variation of action verbs, both on the concrete and the abstract level of representation, an approach to the study of language, such as proposed by the CMT, can help: (a) To better disclose the nature of the relationship that seems to tie up together the primary and metaphorical uses of a given action verb; and (b) to investigate the specific role that bodily-action information plays within our conceptual system (Panunzi and Vernillo 2019).

\subsection{Image Schema Theory}

Image schemas (or schemata) are a key notion in the field of Cognitive Linguistics used to tie up together embodied experience, cognition, and language. The early notion of the concept dates to the empirical works on spatial relations terms by Talmy (1983) and Langacker (1987), but it has been fully developed only a decade later by Johnson (1987) and Lakoff (1987). Image schemas have been investigated not only in 
Cognitive linguistics but in many research fields, amongst others, Psycholinguistics (Gibbs and Colston 1995), Developmental Studies (Mandler 1992; Mandler and Cánovas 2014), Poetics (Lakoff and Turner 1989), and Neurosciences (Feldman and Narayanan 2004; Gallese and Lakoff 2005).

Image schemas are deemed to be imaginative structures of understanding; by their means, we can make sense of our everyday bodily functioning and physical interaction within the surrounding space. They directly emerge from bodily experience and represent a sort of bridge between sensory-motor information and higher cognitive functions (Hampe 2005). According to Johnson's (1987: XIV) traditional definition, an image schema is a 'recurring, dynamic pattern of our perceptual interactions and motor programs that gives coherence and structure to our experience'. In the literature, the umbrella term image schema has been subject to different interpretations and has thus resulted in a large cross-linguistic variation in the use of the term itself (Mandler and Cánovas 2014; Talmy 1983). Although there is no general agreement upon the definition of the concept, there is broad consensus that image schemas are characterized by a stable set of recurrent properties (Cienki 1997; Gibbs 2006; Hampe 2005; Hampe and Grady 2005; Johnson 1987; Krzeszowski 1993; Lakoff 1987):

a. They recur across a large variety of distinct experiences and are not bound to a particular context of experience and knowledge;

b. They are preconceptual primary components, that is, unlike propositions, they do not state the truth or other conditions of satisfaction;

c. They are characterized by having an internal gestaltic configuration (they contain a small number of related parts and intended as coherent and meaningful wholes);

d. They tend to be co-experienced together (e.g., superimposition);

e. They show an orientation towards the positive or negative default evaluation when used in metaphorical mappings (plus-minus or axiological parameter);

f. They have both a static and dynamic nature (they can represent either a state of being or processes);

g. Their internal structure of image support inferences; and

h. They operate beneath the level of our conscious awareness.

A condensed inventory of the image-schematic structures which most frequently recur in our experience is provided in Johnson (1987). The list is not conceived as a closed set but rather as the result of an informal analysis (or reflective interrogation) of the most basic phenomenological features of our every-day experience. Different approaches to the identification and categorization of image-schematic structures have been proposed by Mandler (1992), Talmy (2000), Mandler and Cánovas (2014). Beyond the differences between the various taxonomic proposals, some of the most frequently cited examples of image schemas are CONTAINMENT, SOURCE PATH GOAL, VERTICAL AXIS, FORCE, SUPPORT.

Image schemas are operative in our perceptual interactions, bodily movements, and physical manipulation of objects since early infancy (Mandler 1992; Mandler and Cánovas 2014). They are recognized as primitive cognitive components in the 
development of human thought. These conceptual building blocks encode not only spatial $^{3}$ and bodily related information but also play an essential role in the modeling of highly abstract concepts (e.g., over in Lakoff 1987 and Brugman 1988; verticality in Ekberg 1995; straight in Cienki 1998; smooth-rough in Rohrer 2006). Skeletal projections of image schemas are transferred from domain to domain through analogical reasoning and metaphorical mapping (Kövecses 2010). In the operation of metaphorical mapping, image schemas constrain the information transfer in such a way to prevent the source domain topology from incoherence or inconsistency with the internal structure of the target domain (Invariance principle; Lakoff 1990, 1993; Turner 1991).

Since this linguistic investigation rests on the basic idea that physical experiences can be thought of as one of the most important sources that give meaning to conceptual structures, my analysis strongly benefited from the adoption of an image-schematic approach to the study of language. As I will show in the next paragraphs, the differential image-schematic structures characterizing the semantic core of action verbs strictly impinge on their extension and, consequently, their metaphorical potential. They determine the type of abstract concepts (and figurative meanings) that may or may not be conveyed by the action predicates. Against this background, the detection of the image schemas operating within the primary variation of action verbs helped on two levels of the analysis: first, image schemas may be used to motivate the synonymousness relations between two action verbs (e.g., both spingere and premere may be used to express the same action concept); and second, to understand the divergent or convergent behaviors that two action verbs have when used to encode abstract concepts and figurative meanings (e.g., the verbs spingere and premere are not always used to convey the same kind of metaphorical concepts).

\section{Data and Methods}

This study aims at investigating the semantic variation of a cohesive group of four action verbs that, in their basic meaning, codify the exertion of physical force: premere (Eng., to press), spingere (Eng., to push), tirare (Eng., to pull) and trascinare (Eng., to drag). The data the analysis was built upon have been primarily extracted from the corpus IMAGACT (Moneglia 2014a, b) and later integrated with a larger number of occurrences taken from the Opus corpus (Italian subtitles). The annotation process started with the scrutiny of more than 5000 occurrences, of which about 1000 were derived from IMAGACT and around 4000 from the Opus corpus. Interestingly, just a small part of the whole collection became the classification core. This means that the analysis of the metaphorical production (i.e., marked variation) of the four action verbs was only based on 300 metaphorical occurrences.

\footnotetext{
${ }^{3}$ According to Mandler (1992), Mandler and Cánovas (2014) spatial inputs are recoded in the form of image schemas during processes of perceptual meaning analysis and used as primitive conceptual components in the development of human thought.
} 
With regard to the deep annotation process, it can be spelled out in the following three crucial steps:

1. Overall evaluation of the primary variation of each action verb with the extraction of the significant semantic properties with a strong distinctive value (e.g., differences in motor schemas, spatial relations, type of object involved, action participants);

2. Examination of the metaphorical uses of each action verb and isolation of the metaphorical conceptual structures found within their marked variation (Lakoff et al. 1991; MetaNet: Dodge et al. 2013);

3. Identification of the most salient image-schematic components (Johnson 1987; Lakoff 1987; Mandler and Cánovas 2014) for each verb, with respect to its primary and marked variation.

\section{Description of the Primary Variation of the Four Action Verbs}

The four general action verbs premere (Eng., to press), spingere (Eng., to push), tirare (Eng., to pull), and trascinare (Eng., to drag) can be looked at as a cohesive semantic class, in which the category of force-dynamics represent the main actor. They are, in fact, all used to express the exertion of some kind of physical force on the agent's body, animate theme, or tangible object. To simplify the representation of their semantic variations and the isolation of the common and differential traits, the presentation has been organized by coupling these verbs in 2 sub-groups: (1) one group represented by premere and spingere; (2) the other group represented by tirare and trascinare.

In Sect. 5.1, I will describe the primary variation of premere and spingere, highlighting convergent and divergent points along their axis of variation. In Sect. 5.2, I will focus on the description of tirare and trascinare, and I will try to illustrate their semantic similarities and differences, when their physical (and concrete) uses are considered.

\subsection{The Primary Variation of the Verbs Premere and Spingere}

As locally equivalent verbs, premere (Eng., to press) and spingere (Eng., to push) share a common sub-set of action concepts. They are applied in a small range of linguistic contexts to encode action events in which an agent interacts with an entity by exerting force on it. Interestingly, the entity is not deeply or permanently physically affected by the force and, overall, is not moved from one place to another. Both the verbs, for instance, are employed in the depiction of action events in which the force can result in: (a) An activation of the device connected to the affected entity ("Spingere/premere il pulsante"; Eng., "To push/To press the button"); and (b) the 
establishment of new relations between two or more entities ("Spingere/premere il coperchio sulla scatola"; Eng., "To push/To press the lid on the box").

\subsubsection{The Primary Variation of the Verb Premere}

The equivalence of the verbs premere (Eng., to press) and spingere (Eng., to push) is not absolute and their variations do not tend to systematically converge. Besides the uses presented above, the verb premere also appears to codify action concepts in which the application of force on a specific entity (in the form of physical pressure) results in a mere physical manipulation (e.g., "Il fisioterapista preme sulla schiena di Maria"; Eng., "The physical therapist presses on Mary's back"). With regard to its inherent image-schematic structure, the verb premere bases on the FORCE schema and, unlike spingere, never entails the MOTION schema. The verb premere is mainly used to profile static scenarios, that is, to highlight the mere interaction between a force and the entity affected by the exertion of the force. Given the prototypical action imagery associated with premere, the image-schematic components which appear to play a relevant role in its primary variation are: COMPULSION FORCE, CONTACT, OBJECT, and BLOCKAGE.

\subsubsection{The Primary Variation of the Verb Spingere}

The verb spingere (Eng., to push) commonly expresses action events in which the exertion of force on a concrete entity has the motion as direct entailment. The motion can either be instantiated by an external force (e.g., CAUSED MOTION: "Spingere il carrello"; Eng., "To push the cart down the hall") or be spontaneous and not brought about by another force (e.g., SELF- PROPELLED MOTION: "Il nuotatore si spinge con le gambe"; Eng., "The swimmer pushes himself off of the wall"). Moreover, motion can be continuous and controlled by the agent along the overall path (e.g., CAUSED JOINT MOTION schema); or it can be discrete and controlled by the agent only in the initial phase of the event (e.g., CAUSED MOTION schema). The former MOTION schema plays a central role in the construal of those action events in which the agent has control of the theme throughout the motion (e.g., "Spingere il carrello"; Eng., "To push the chart down the hall"). The latter schema is determinant in those action events in which the agent does not experience the overall motion of the theme, and in which the motion results in a different spatial agent-theme configuration, such as in an increase of the physical distance between the agent and the entity affected by the force (e.g., "Spingere la scatola"; Eng., "To push the box away"). As the verb structure suggests, the tight association between the FORCE and the MOTION schemas is a distinctive feature of the semantic core of spingere. Rather than being used to encode events of mere force exertion, the verb spingere is mainly used in the encoding of kinetic events, that is, in events involving the shift of the location of the affected entity (animate or inanimate). As the prototypical action imagery associated with spingere suggests, the image-schematic components which do play a relevant role 
Table 2 Differential image schemas in the variation of premere and spingere

\begin{tabular}{l|l|l|l|l|l}
\hline \multicolumn{2}{l}{ Differential image schemas } & \multicolumn{7}{l}{} \\
\hline & Contact & Compulsion force & Motion & Path & Object \\
\hline Premere & + & + & - & - & + \\
\hline Spingere & + & + & + & + & $+/-$ \\
\hline
\end{tabular}

in the verb primary variation are: COMPULSION FORCE, CONTACT, OBJECT, PATH, and SELF/CAUSED MOTION.

To give a general overview on the image schemas that I discussed so far, in the table below, I present a brief resume of the different components involved in the semantic core of the action verbs premere (Eng., to press) and spingere (Eng., to push), and I distinguish between salient (+), absent (-), and optional schemas (+/) (Table 2).

\subsection{The Primary Variation of Tirare and Trascinare}

When we use tirare (Eng., to pull) and trascinare (Eng., to drag) as locally equivalent verbs, we probably want to refer to action events in which an agent exerts a physical force (COMPULSION FORCE schema) on a theme (either animate or inanimate), such as to forcefully and roughly move it along a surface (CAUSED JOINT MOTION schema). ${ }^{4}$ The force can be either directly applied on the affected entity (e.g., "Fabio tira/trascina il sacco della spazzatura"; Eng., "Fabio pulls/drags the garbage") or be indirectly applied using an intermediary instrument ("Giovanni tira/trascina la barca con l'argano"; Eng., "John pulls/drags the boat onto the beach with the winch"). The transfer of the object (e.g., theme) on the terrain does not happen smoothly, but it encounters some difficulties which slow down the motion of both entities which are involved (e.g., the agent and the theme). The slowing down may be caused by either the fact that the theme has a weight that impedes its motion or by the theme's reluctance to move along the path (BLOCKAGE schema). Either way, the verbs tirare and trascinare profile an action scene in which, at each step of the motion, the agent tries to forcefully overcome the resistance produced by the friction between the theme and its path along which the theme moves (RESTRAINT REMOVAL schema).

\subsubsection{The Primary Variation of the Verb Tirare}

The verbs tirare (Eng., to pull) and trascinare (Eng., to drag) are tied up in a relationship of partial synonymy, that is, they are not always applicable in the same linguistic contexts. The semantics of the verb tirare is based on a larger array of action events

\footnotetext{
${ }^{4}$ The agent has control of the theme throughout the motion and not only in the beginning phase of the force-action event.
} 
Table 3 Differential image schemas in the variation of tirare and trascinare

\begin{tabular}{l|l|l|l|l|l|l|l|l}
\hline \multicolumn{1}{l}{ Differential image schemas } \\
\hline & Contact & $\begin{array}{l}\text { Compulsion } \\
\text { force }\end{array}$ & $\begin{array}{l}\text { Restraint } \\
\text { removal }\end{array}$ & Blockage & Motion & Path & Object & Surface \\
\hline Tirare & + & + & $+/-$ & $+/-$ & $+/-$ & $+/-$ & + & $+/-$ \\
\hline Trascinare & + & + & + & + & + & + & $+/-$ & + \\
\hline
\end{tabular}

and schemas. In general, the predicate describes action scenes in which the force applied may or may not result in events of proper motion. In cases where it does, the predicate describes events in which an agent causes an object to move along a path (e.g., CAUSED MOTION ${ }^{5}$ ). The motion can be performed either along the vertical or the horizontal axis, and it is normally supposed to be directed towards the agent or towards the effector who applied the force. In cases in which the exertion of force does not result in a schema of motion, the predicate is used to profile action events involving the mere manipulation or modification of the shape of an object (e.g., "Mario tira la corda"; Eng., "Mario pulls the rope"). Given the prototypical action imagery associated with the verb tirare, the following image-schematic components were isolated: COMPULSION FORCE, OBJECT, CONTACT, PATH, and CAUSED/CAUSED JOINT MOTION.

\subsubsection{The Primary Variation of the Verb Trascinare}

The verb trascinare (Eng., to drag) has a primary variation narrower than that of the verb tirare, as it is only used to encode action events in which the motion is performed in the same agent or effector's direction (CAUSED JOINT MOTION schema). The verb trascinare can also be used to name physical events of SELF- PROPELLED MOTION, that is, events in which an animate entity moves along a path spontaneously, without the intervention of an external force (e.g., "Fabio si trascina lungo il corridoio"; Eng., "Fabio drags himself along the ground"). In both the cases (CAUSED and SELF- PROPELLED MOTION schemas), the predicate encodes action events in which the existence of a frictional force influences the specific manner of motion along the path (the motion is performed forcefully and roughly). As the analysis of the action imagery associated with the verb trascinare suggests, the following image schemas are relevant within its semantic core: COMPULSION FORCE, OBJECT, CONTACT, PATH, SELF/CAUSED JOINT MOTION, SURFACE, BLOCKAGE, RESTRAINT REMOVAL.

The following table proposes a set of differential image-schematic components that allow the better understanding of the application conditions of tirare (Eng., to pull) and trascinare (Eng., to drag) and I distinguish between salient (+), absent (-), and optional schemas (+l-) (Table 3).

\footnotetext{
${ }^{5}$ Unlike trascinare, the verb tirare does not encode the image schema SELF- PROPELLED MOTION.
} 


\section{Description of the Marked Variation of the Four Action Verbs}

In the previous Sections, it has been claimed that the semantics of general action verbs is strongly tied to specific perceptual, spatial, and motor schemas. It has been shown that the semantic variation of two similar action verbs (e.g., premere and spingere; tirare and trascinare) can partially converge and be responsible for their mutual use in the operation of action reference and labeling. However, it has also been pointed out that these same verbs can also be applied in diverse pragmatic contexts to express diverse types of action events. The question I want to investigate is whether these couplings extend the same kind of interwoven semantic relations to their marked variations. Their pervasiveness, though, not manifests itself only on the level of the reference to concrete actions, but also on a more abstract one, where the semantic core is exploited to encode figurative meanings (i.e., marked variation), springing from largely metaphorical processes.

In the following Sections, it will be shown how different semantic properties of the predicates connect to a different type of metaphors and metaphorical meanings. In particular, in Sect. 6.1, the most significant types of metaphors detected within the marked variation of premere (Eng., to press) and spingere (Eng., to push) will be analyzed and compared. Finally, in Sect. 6.2, the metaphorical uses of tirare (Eng., to pull) and trascinare (Eng., to drag) will be spelled out. The analysis will not only consider the conceptual metaphorical structures needed to explain the array of abstract uses identified in the verb's semantics, but it will also identify the image schemas that are salient in the operation of metaphorical meaning construction.

\subsection{The Marked Variation of the Verbs Premere and Spingere}

It often happens that the verbs premere (Eng., to press) and spingere (Eng., to push) are co-extensively used to linguistically express the same kind of metaphorical concepts. Both the verbs are involved in the encoding of the general conceptual metaphor PSYCHOLOGICAL FORCES ARE PHYSICAL FORCES, via which psychological manipulation (e.g., impact or influence) is understood in terms of physical manipulation (e.g., contact or pressure):

(9) "L'oratore preme sui temi sociali"

"The speaker is pressing on social agenda"

(10) "Occorre premere sulle due parti perché il negoziato sia vero"

"We need to put pressure on the parties to make the agreement true"

(11) "Bisogna spingere sui processi di liberalizzazione"

"We need to put pressure on the deregulation processes"

"Abbiamo spinto affinché tale diritto sia reso più accessibile"

"We pushed to make this right more accessible" 
The verbal items in (9-12) exploit our knowledge of the category of force dynamics in the representation of the psychological interaction between two entities: the source of the force (ANIMATE ENTITY schema) and the party affected by the force (OBJECT schema). The sentences (9-12) represent, on the level of language, the projection of the abstract domain of psychological forces (e.g., influence) into the concrete domain of physical forces (e.g., pressure).

\subsubsection{The Marked Variation of the Verb Premere}

Unlike spingere (Eng., to push), the verb premere (Eng., to press) is often used to describe a situation in which the entity exerting the force is perceived as a burdensome object (OBJECT schema), weighing on another entity or theme (OBJECT and SUPPORT schema) through a sort of imagery contact:

$$
\begin{aligned}
& \text { "La disoccupazione preme sulla spesa sociale" } \\
& \text { "Unemployment weighs on public expenditure" }
\end{aligned}
$$

Example (13) is a linguistic variation of the metaphor IMPEDIMENTS TO IMPROVING ECONOMIC STATUS IS PHYSICAL BURDEN which represents a complex case of the primary metaphorical structure DIFFICULTIES ARE IMPEDIMENTS TO MOVEMENT. The sentence frames a very specific scene in which unemployment (OBJECT schema) is conceived as a social burden or as an obstacle (BLOCKAGE schema) that weighs on (COMPULSION FORCE schema) the public spending. More in general, the verb premere appears to be pervasively used in the picturing of metaphors that exploit our experience of and response to burdens and loads to structure more highly abstract domains. In the same way that when I say that "Il tempo preme" (Eng., "Time is pressuring me"), I am not referring to the fact that I may eventually change the situation in which I am because of the time pressure. I am focusing on the fact that another entity (e.g., time) is exerting a psychological force (conceived in terms of pressure), that the same entity is affecting my state of mind, and that I may be weighed down by the force itself. In similar cases, the direct contact between the source and the target entity does result in a sort of burdensome stasis or mere physical pressure, without implying a change of state or action of the target entity. This fact can be connected to the fact that, as I said in (4.1.1), the action imagery associated with the verb premere does not entail the image schema of MOTION. As a consequence, this action verb is mainly used to represent static scenarios, that is, to express the mere interaction between a force and the entity affected by the force.

\subsubsection{The Marked Variation of the Verb Spingere}

The verb spingere (Eng., to push) rather appears in contexts where the encoding of more dynamic metaphorical concepts is based on the source domain of MOTION: 


$$
\begin{aligned}
& \text { "Le circostanze spingono Fabio ad agire" } \\
& \text { "Circumstances are pushing Fabio to act" } \\
& \text { "La situazione si spinge verso l'anno successivo" } \\
& \text { "The situation will press on into the next year" } \\
& \text { "L'amministratore spinge avanti l'azienda" } \\
& \text { "The manager pushes the company forward" }
\end{aligned}
$$

The metaphorical extensions presented above (14-16) conceptualize causation in terms of motion (either caused or self-initiated). In example (14), external forces (e.g., circumstances) are intended in terms of animacy (ANIMATE ENTITY schema) and cause (COMPULSION FORCE schema) that a second target entity (e.g., Fabio: ANIMATE ENTITY schema) performs an action or adopt a set of actions and, eventually, behaviors (e.g., CAUSED MOTION schema). Importantly, this example bases on the generalization that caused change of action is conceived as forced motion relative to a location. The expression in (14) can be seen as the linguistic reflection of the complex conceptual metaphor CAUSED CHANGE OF ACTION IS CONTROL OVER AN ENTITY RELATIVE TO A LOCATION, which is an entailment of the metaphor CHANGE OF ACTION IS CHANGE OF MOTION. This conceptual structure also makes use of the metaphors CAUSES ARE FORCES and CAUSATION IS OBJECT TRANSFER. In example (15), an event is seen as a moving entity (ANIMATE ENTITY schema) directed from one location in space (SOURCE POINT FOCUS schema) to another (END POINT FOCUS schema). The changing that the event undergoes is understood as self-initiated motion (SELF- PROPELLED MOTION schema). The example (15) is a linguistic variant of the metaphor THE PROGRESS OF EXTERNAL EVENT IS A FORWARD MOTION, ${ }^{6}$ but may also be understood in a more general metaphorical scenario in which TIME is conceptualized as a LANDSCAPE WE MOVE THROUGH and ACTION is conceived as SELF- PROPELLED MOTION. ${ }^{7}$ Finally, example (16) can be connected to the conceptual metaphor CONTROL OVER ACTION IS CONTROL OVER MOTION, which is a special subcase of the conceptual metaphor PURPOSEFUL ACTION IS DIRECTED MOTION TO A DESTINATION (CAUSED JOINT MOTION schema). This metaphor also entails the metaphorical structure PROGRESS IS FORWARD MOTION ALONG THE PATH. In this and in example (14), causation is intended in terms of forced motion relative to a region or a path. The main difference is the fact that the metaphorical extension in (16) bases on action imagery slightly different from the one found in (14). In this last example, the verb spingere does not only encode forced motion (CAUSED MOTION schema) but also the idea that forced motion is controlled along the overall path (CAUSED JOINT MOTION schema). An animate and forceful entity (e.g., the manager) may have a specific purpose (e.g., the development of the company) and may want to guide the target entity (OBJECT schema) that she controls (e.g., company) toward the final goal of the long-term, purposeful action she is bringing about (END POINT FOCUS schema).

\footnotetext{
${ }^{6}$ This metaphor is an entailment of PROGRESS IS FORWARD MOTION ALONG THE PATH.

${ }^{7}$ It is a subcase of the metaphor ACTION IS MOTION ALONG THE PATH.
} 
The combination of the FORCE and MOTION schema is also salient in the encoding of the orientation metaphorical extensions by the verb spingere. This is in those uses in which the predicate expresses the change of a certain value along a measurable scale:

"Tali fattori hanno spinto verso l'alto i prezzi"

"These factors pushed up the prices"

"I rincari hanno spinto l'inflazione verso valori superiori al 2\%"

"Price increase pushed the inflation over $2 \% "$

Both cases (17-18) can be linked to the metaphor CAUSE INCREASE IN QUANTITY IS CAUSE UPWARD MOTION, entailment of the more general primary metaphor MORE IS UP, and of the metaphor CAUSED CHANGE OF STATE IS CAUSED CHANGE OF LOCATION. The metaphorical mapping is built upon image-schematic knowledge: while the target domain (e.g., QUANTITY) makes use of the SCALE schema, the source domain (e.g., CAUSED UPWARD MOTION) makes use of the combination of the image schemas of COMPULSION FORCE, CAUSED MOTION and VERTICAL ORIENTATION.

Taken together, in all explained examples (14-18), there are two points especially interesting for my analysis: first, the category of force systematically intersects with that of motion; and second, unlike premere, the verb spingere encodes this constant semantic combination in the unravelment of both its primary and metaphorical variation.

\subsection{The Marked Variation of the Verbs Tirare and Trascinare}

The metaphorical variation of the verbs tirare (Eng., to pull) and trascinare (Eng., to drag) usually converge to the encoding of those conceptual metaphors that construe the domain of CAUSATION on the basis of the domains of FORCE and MOTION. The two predicates are involved in the linguistic representations of a large system of metaphors in which causation is connected to animacy (e.g., CAUSATION IS AGENTIVE CAUSATION), causes are intended in terms of force (e.g., CAUSES ARE FORCES), changes of state (or of action) are conceptualized as changes of motion (e.g., CAUSATION IS CONTROL OVER AN ENTITY RELATIVE TO A LOCATION):

(19) "Marco tira Luca nella conversazione"

"Marco involves Luca in the conversation"

(20) "Il governo non tirerà l'Algeria fuori dal solco in cui si trova"

"The government will not get Algeria out of its current situation"

(21) "Ci hai trascinato in mezzo ai guai"

"You dragged us in a lot of problems"

(22) "Il presidente ha trascinato il paese sul fondo"

"The president dragged the country down" 
In examples (19-22), the verbs tirare and trascinare are used to depict metaphorical scenes in which the change of state of the affected entity is caused by an external entity (ANIMATE ENTITY schema). The agent has control over the whole process of transition from a state to another (PATH schema), and causes (COMPULSION FORCE schema) that the final state or goal achieved by the affected entity is intended in terms of motion from one location to another (CAUSED JOINT MOTION schema). ${ }^{8}$ As the analysis of the examples shows, there exists an evident correspondence between the metaphorical extensions of the verbs tirare and trascinare, and the specific sensorymotor imagery associated with these same predicates. All the metaphorical items discussed above (19-22) are built upon an operation of conceptual mapping in which:

a. The agent corresponds to the agent that leads the motion;

b. The party affected by the new situation or process corresponds to the entity (animate or inanimate) moved by the agent along the path;

c. The caused change of state or situation corresponds to the motion caused by the agent;

d. The achievement of the final goal corresponds to the reach of the final location along the path.

\subsubsection{The Marked Variation of the Verb Trascinare}

The metaphorical variation of the verb trascinare (Eng., to drag) diverges from that of tirare in many points. The systematic combination of the FORCE and MOTION schemas stands as the thread that deeply connects the sets of different metaphorical uses produced by the verb. Nevertheless, either the MOTION and the FORCE schemas (and imageries) associated with the predicate are richer and more complex than those involved in the variation of tirare, as they seem to be more semantically constrained. Unlike tirare, the verb trascinare does not simply encode the schema of CAUSED MOTION but also that of SELF- PROPELLED MOTION. The verb does also require a specific manner of motion (frictional, ${ }^{9}$ forceful, and difficult). With regard to the FORCE schema, the verb trascinare requires that the target entity is reluctant or difficult to move (BLOCKAGE schema) and that the force moving the target entity (COMPULSION FORCE schema) tries to continuously overcome that physical restraint (RESTRAINT REMOVAL schema). The metaphorical items identified within the variation of trascinare confirm the saliency of all the semantic aspects discussed above (see also Sect. 5.2). The CAUSED MOTION image schema seems to play a structural role within the modeling of many metaphorical uses:

\footnotetext{
${ }^{8}$ The change of state can be enriched with additional space information and represented as a motion performed along a bounded path (CONTAINER schema) or along the vertical axis (VERTICAL AXIS schema).

${ }^{9}$ The verb trascinare (Eng., to drag) always implies a sort of friction between the moving entity and the ground along which the entity moves.
} 


$$
\begin{aligned}
& \text { "Gli eventi trascinano la massa" } \\
& \text { "The events are dragging people [along]" } \\
& \text { "L'odio ti trascina" } \\
& \text { "Hatred tugs on you" } \\
& \text { "L'attore trascina il pubblico" } \\
& \text { "The actor drags the audience along" } \\
& \text { "Il tifo non trascina nessuno" } \\
& \text { "The cheer does not grab [lit., drag] anyone" }
\end{aligned}
$$

Sentences (23-26) profile an extremely unbalanced system of forces, in which one entity (an agent, external event, process, or emotion) is conceptualized in terms of volition and animacy, and impinges on a second entity's behavior, state, or action. The general conceptual metaphors to which we can relate these examples are the same as cited in the previous Section (e.g., CAUSATION IS AGENTIVE CAUSATION, CAUSES ARE FORCES, and CAUSATION IS CONTROL OVER AN ENTITY RELATIVE TO A LOCATION). What happens to be very interesting here (23-26) is that the verb tirare cannot be applied in these same metaphorical contexts to express the same kind of metaphorical meaning. The kind of force encoded by tirare does not happen to entail the same state of unbalance (and of the unbalanced ratio between the entities and the forces involved) that seems to be a salient feature at the base of all the metaphorical extensions expressed by trascinare. Unlike tirare, the verb trascinare always entails the existence of a sort of impediment to motion and, hence, the presence of a specific bodily response to that same impediment: the verb trascinare entails that the motion (and the action) is performed with difficulty and that difficulty increases the effort needed to accomplish an objective or to reach a goal (e.g., conceptual metaphor DIFFICULTIES ARE IMPEDIMENTS TO MOVEMENT).${ }^{10}$ For the same reason, the verb trascinare is mainly used to encode metaphors that imply a slightly negative meaning. The same characteristics discussed so far seem to be relevant to the metaphorical extensions of the verb trascinare that rely upon a different type of motion schema, that is, the self-propelled motion schema. In the case of self-propelled motion, instead of being affected by an external force, one entity moves spontaneously with its direction:

$$
\begin{aligned}
& \text { "Il conflitto si trascina da anni" } \\
& \text { "The war drags on for years" } \\
& \text { "Gianni si trascina in un' esistenza spaventosa" } \\
& \text { "Gianni is dragging himself into an awful existence" }
\end{aligned}
$$

Examples in (27-28) have different meanings and refer to different abstract concepts, but both can be linked to the primary conceptual metaphor SELF- PROPELLED ACTION IS SELF- PROPELLED MOTION. While in the first sentence (27) the moving entity is represented by a long-lasting event (e.g., TIME IS A LANDSCAPE IN WHICH EVENTS

\footnotetext{
${ }^{10}$ For the same reason, the verb trascinare (Eng., to drag) is mainly used to encode metaphors that imply a slightly negative meaning (see plus-minus parameter in Krzeszowski 1993).
} 
MOVE THROUGH), ${ }^{11}$ in the second example (28) the moving entity is represented by a person, a volitional, and animate entity, who laboriously drags herself in a painful and difficult situation. Interestingly, in (27-28), the verb tirare cannot be applied since it does not happen to encode, with its semantic core, the schema of SELF- PROPELLED MOTION. On the contrary, in these sentences, the verb trascinare is perfectly usable since it also codifies the SELF- MOTION schema in its primary variation.

\subsubsection{The Marked Variation of the Verb Tirare}

As we saw in examples (19-20), the verb tirare (Eng., to pull) is mostly used to encode causation events, that is, to profile metaphorical scenarios in which one entity causes another entity to be affected by the occurrence of a new event or state (e.g., CONTROL OVER ACTION IS CONTROL OVER MOTION, CAUSED CHANGE OF STATE (or ACTION) IS CAUSED CHANGE OF MOTION, etc.). Interestingly, this verb often encodes causation events which entail a specific spatial relationship between the agentive force and the entity affected by the force:

$$
\begin{aligned}
& \text { "Non hai speranze di tirarmi dalla tua parte" } \\
& \text { "You cannot get me on your side" } \\
& \text { "Sandra tira sempre" } \\
& \text { "Sandra is attractive" }
\end{aligned}
$$

Metaphors in (29-30) show that the PATH schema involved in the semantic core of tirare entails that the shift from point A (start point focus schema) to point B (END POINT FOCUS schema) which is performed by the entity affected by the force corresponds to the spatial location of the source of the force. The verb implies that the motion is directed towards the actor, that is, towards the source of the force (TOWARDS TO schema; NEAR FAR schema). More in particular, the example (29) is a subcase of the metaphorical structure AGREEMENT IS BEING ON THE SAME SIDE (OR AGREEMENT IS PROXIMITY), in which physical closeness is the source domain for metaphors of similarity, solidarity, and support. The example (30) may be seen as a linguistical extension of the conceptual metaphors DESIRES THAT CONTROL ACTION ARE EXTERNAL FORCES THAT CONTROL MOTION ${ }^{12}$ and DESIRES ARE FORCES BETWEEN THE DESIRED AND THE DESIRER. Thereby sexual attraction is interpreted as a force toward physical proximity or closeness (e.g., ATTRACTION FORCE schema), and the desired object is interpreted as a desired state or location. The verb trascinare cannot be applied in similar metaphorical contexts, for two main reasons: first, its action-motion schema presupposes that both the agent and

\footnotetext{
${ }^{11}$ Interestingly, when the moving entity is represented by an inanimate entity, the verb trascinare always encodes figurative meanings in which the duration of a process (event or situation) is measured in terms of motion along a path.

${ }^{12}$ This metaphor also could be associated with example (25). Nevertheless, the verb trascinare does not bring along the same kind of inferential structure as tirare and does not entail that the attraction force between the agent and the target entity results in a different spatial configuration between the two.
} 
the affected entity are in motion (CAUSED JOINT MOTION schema); and second, even though they move in the same direction (the agent's direction), the final point reached by the affected entity does not correspond to the agent's location and does not result in a sort of shortening of the distances between the entities (TOWARDS TO schema; NEAR FAR schema). The verb tirare seems to be also pervasively used in the encoding of orientational metaphors, that is, metaphors whose mapping organizes target concepts by means of very basic spatial vectors, such as up-down, near-far, in-out, center-periphery, and so on:

$$
\begin{aligned}
& \text { "L'insegnante tira su il voto di Luca" } \\
& \text { "The teacher raises Luca's grade"13 } \\
& \text { "Ho provato a tirarlo su" } \\
& \text { "I tried to cheer him up" }
\end{aligned}
$$

In the example (31), the PATH schema is conceived as a SCALE, i.e., as a vertical path, whose points are not intended as neutral points but as values. It profiles a scenario in which an actor (ANIMATE ENTITY) causes an entity (OBJECT schema) to change position on a scale. The change of position from a point (START POINT FOCUS schema) to another (END POINT FOCUS schema) results in a change of state of the object (here conceived as a value). The metaphorical extension in (31) can be interpreted as a lexical representation of the metaphor CAUSE INCREASE IN QUANTITY IS CAUSE UPWARD MOTION, which is a special case of the more general and primary conceptual metaphor MORE IS UP. Finally, example (32) represents a scenario in which the passage from a negative to a positive emotional state is conceptualized in terms of upward motion, this is caused by an external force or entity. The expression is a case of the conceptual metaphor CAUSE CHANGE IN MOOD IS VERTICAL MOTION, which is a subcase of the primary metaphor HAPPY IS UP (or IMPROVEMENT IN MOOD IS UPWARD MOTION).

\section{Discussion of the Results}

This work focused on the semantic description of four action verbs encoding force, i.e., premere (Eng., to press), spingere (Eng., to push), tirare (Eng., to pull), and trascinare (Eng., to drag). The analysis was organized in a way to simultaneously compare two pairings of verbs: on the one hand, similarities and differences between the verbs premere and spingere were presented; on the other hand, convergences and divergences between tirare and trascinare were explained.

\footnotetext{
${ }^{13}$ The action verb trascinare (Eng., to drag) cannot be applied to encode the metaphorical increase (or decrease) of a value along an imagery VERTICAL AXIS (SCALE schema). This predicate can only be used to encode force-motion events along the horizontal axis. The kind of force encoded by trascinare, in fact, presupposes that the gravitational steady state of the entities involved in the event does not change. The entities must move along the ground (or horizontal path), producing a continuous frictional force.
} 
With regard to the primary variation, it has been shown that the action verb premere (Eng., to press) only applies to contexts in which the state of the theme affected by the force does not result in any form of motion (BLOCKAGE schema). Additionally, it has been stressed that premere focuses on the pure exertion of force (in the form of physical pressure), i.e., on the interaction between the entity that applies the force and the object towards which the same force is directed. Unlike premere, the other three verbs encode the MOTION schema within their inner semantic skeleton, thus being used to profile more kinetic action scenes. Both the verbs spingere (Eng., to push) and tirare (Eng., to pull) have very flexible semantics, being able to encode different types of action events (with or without the association of force and motion). Nevertheless, they mainly focus on the result of the forceful interaction between the entities involved in the action, that is, on the directed caused motion to which the object is subject to. In spingere, the motion is normally thought to be directed from the point of contact between the effector and the object and away from the agent; in tirare, the motion is normally thought to be directed from the point of contact between the effector and object, and towards the agent. Finally, the verb trascinare (Eng., to drag) represents a very specific case, as it requires a greater number of necessary components for its application, and always needs the CAUSED JOINT MOTION and the RESTRAINT REMOVAL schemas to be activated. As a matter of fact, in trascinare the application of force happens to be always associated with the MOTION schema., and it is, in some way, limited by the fact that the object has a weight and may be reluctant to move. These two facts currently represent a restraint that is going to be constantly removed to move the object along the surface it lies upon.

This study not only aimed at showing how the semantics of action words mirrors the way in which we internally structure the logic of metaphorical concepts. As it has been stressed throughout the analysis, the differential semantic traits that characterize the four predicates strictly influence their metaphorical potential. When their semantic network converges, it is easier to detect the reasons why these predicates can be equally applied to express the same figurative meanings. On the contrary, when their semantic extensions start to diverge, we may wonder how it is possible that some metaphorical concepts can be accessed by one verb and not by the other. On the basis of the data, I suggest that for a metaphor to be expressed in a specific context, the predicate must contain specific schemas pertaining to that context. With respect to the evaluation of these four action verbs semantics:

(a) Metaphors involving the target domains of PSYCHOLOGICAL MANIPULATION, INFLUENCE or IMPACT are enabled by the presence of the FORCE (exerted in the form of a pressure) image schema and have been encountered in the variation of the predicates premere and spingere;

(b) Metaphors encoding CAUSATION are enabled by the combination of the FORCE and MOTION image schemas, and have been detected only along the semantic variation of spingere, tirare and trascinare;

(c) Metaphors encoding self-propelled changes of state or action are enabled by the combination of the FORCE and SELF- PROPELLED MOTION image schemas, and have been only found in the metaphorical production of spingere and trascinare; 
Table 4 Metaphorical potential of the four action verbs

\begin{tabular}{l|l|l|l|l|l}
\hline Metaphor type & Image schemas & Premere & Spingere & Tirare & Trascinare \\
\hline $\begin{array}{l}\text { Manipulation, } \\
\text { influence, impact }\end{array}$ & Force & + & + & - & - \\
\hline Causation & Force, caused motion & - & + & + & + \\
\hline $\begin{array}{l}\text { Self-caused change of } \\
\text { state or action }\end{array}$ & $\begin{array}{l}\text { Force, self-propelled } \\
\text { motion }\end{array}$ & - & + & - & + \\
\hline Spatial orientation & $\begin{array}{l}\text { Force, motion, vertical } \\
\text { orientation }\end{array}$ & - & + & + & - \\
\hline
\end{tabular}

(d) Orientational metaphors are enabled by the presence of the VERTICAL ORIENTATION image schema and have been identified only with the annotation of spingere and tirare, which happen to be less spatially constrained than, say, trascinare.

The following table schematizes the relationship between the verbs and their metaphorical potential (Table 4).

\section{Conclusions}

The data extracted from the semantic variation of the verbs premere (Eng., to press), spingere (Eng., to push), tirare (Eng., to pull) and trascinare (Eng., to drag) suggest that the metaphorical extensions of these action verbs are not randomly produced but are the result of metaphorical processes in which sensory-motor information and specific image-schematic features are transferred from one domain to another, to enable the representation of highly abstract concepts. In particular, it was shown that differential semantic properties (and image-schematic structures) characterizing the verbs strictly impinge on their metaphorical potential, determining, in some way, the type of metaphorical items that may or may not be expressed (Lakoff 1990, 1993; Turner 1991). The analysis also shows that the same differential semantic properties (and image-schematic structures) are also responsible for the type of partial equivalence that can be established between the action verbs (e.g., premere and spingere), either when their primary or marked variations are considered. In this sense, the investigation of the action verbs' semantics contributes to a better understanding of the way we use action information and very basic bodily schemas to shape not only the way we think but also the way we talk. Action verbs constitute essential linguistic anchors between sensory-motor experience and abstract knowledge, whose deeper semantic description may be used to a different number of goals and, especially, in the building up and structuring of linguistic resources and ontologies. Even in the IMAGACT ontology, a more articulated characterization of action lexicon may be used to improve the representation of verbs' senses, and to systematically define the linguistic boundaries between sense extensions of similar action verbs (e.g., locally 
equivalent verbs). Finally, the image-schematic approach may be a useful tool in the representation of the metaphorical network activated by each action verb stored in the Ontology. To reframe the research on a more general level, I believe that the current results may give their main contribution to the field of Cognitive Linguistics and semantic studies.

\section{References}

Aziz-Zadeh, L., \& Damasio, A. (2008). Embodied semantics for actions: Findings from functional brain imaging. Journal of Physiology-Paris, 102(1), 35-39.

Barsalou, L. W. (2008). Grounded cognition. Annual Review Psychology, 59, 617-645.

Barsalou, L. W. (2016). Can cognition be reduced to action? Processes that mediate stimuli and responses make human action possible. In A. K. Engel, K. J. Friston \& D. Kragic (Eds.), The pragmatic turn: Toward action-oriented views in cognitive science. Series: Strüngmann Forum Reports (Vol. 18). Cambridge, MA: MIT Press.

Brown, S. W. (2014). From visual prototype of action to metaphors extending the IMAGACT ontology of action to secondary meanings (ISO-10). In H. Bunt (Ed.), Proceedings 10th Joint ISO - ACL SIGSEM, Workshop on Interoperable Semantic Annotation. Reykjavik (pp. 53-56).

Brugman, C. (1988). The story of over. Polysemy, semantics and the structure of the Lexicon. New York: Garland [Originally: M.A. thesis at the University of California, Berkeley, 1981].

Casasanto, D., \& Bottini, R. (2014). Mirror reading can reverse the flow of time. Journal of Experimental Psychology, 143(2), 473-479.

Cienki, A. (1997). Some properties and groupings of image schemas. In M. Verspoor, K. Lee \& E. Sweetser (Eds.), Lexical and Syntactical Constructions and the Construction of Meaning: Proceedings of the Bi-annual ICLA Meeting in Albuquerque July 1995 (pp. 3-15). Amsterdam/Philadelphia: John Benjamins.

Cienki, A. (1998). STRAIGHT: An image schema and its metaphorical extensions. Cognitive Linguistics, 9(2), 107-149.

Desai, R. H., Binder, J. R., Conant, L. L., Mano, Q. R., \& Seidenberg, M. S. (2011). The neural career of sensory-motor metaphors. Journal of Cognitive Neuroscience, 23(9), 2376-2386.

Dodge, E., Hong, J., Stickles, E., \& David, O. (2013). The MetaNet Wiki: A collaborative online resource for metaphor and image schema analysis. In 12th International Cognitive Linguistics Conference (ICLC 12).

Ekberg, L. (1995). The mental manipulation of the vertical axis: How to go from "up" to "out" or from "above" to "behind". In M. Verspoor, K. Dong, \& E. Sweetser (eds), Lexical and Syntactical Constructions and the Construction of Meaning: Proceedings of the Bi-annual ICLA Meeting in Albuquerque July 1995 (pp. 69-88). Amsterdam/Philadelphia: John Benjamins.

Feldman, J., \& Narayanan, S. (2004). Embodied meaning in a neural theory of language. Brain and Language, 89, 385-392.

Gagliardi, G. (2014). Validazione dell'ontologia dell'azione IMAGACT per lo studio e la diagnosi del Mild Cognitive Impairment (MCI). Ph.D. Thesis. Firenze: Università degli Studi di Firenze.

Gallese, V., \& Lakoff, G. (2005). The Brain's concepts: The role of the sensory-motor system in conceptual knowledge. Cognitive Neuropsychology, 22(3/4), 455-479.

Gibbs, R. W. (2005). The psychological status of image schemas. In B. Hampe (Ed.), From perception to meaning: Image schemas in cognitive linguistics. Berlin: Mouton de Gruyter (pp. 113--135).

Gibbs, R. W. (2006). Embodiment and cognitive science. Cambridge: Cambridge University Press.

Gibbs, R. W., Jr., \& Colston, H. L. (1995). The cognitive psychological reality of image schemas and their transformations. Cognitive Linguistics, 6, 347-378. 
Glenberg, A. M., \& Kaschak, M. P. (2002). Grounding language in action. Psychonomic Bulletin \& Review, 9, 558-565.

Hampe, B. (2005). When down is not bad, and up not good enough: A usage-based assessment of the plus-minus parameter in image-schema theory. Cognitive Linguistics, 16(1), 81-112.

Hampe, B., \& Grady, J. (Eds.). (2005). From perception to meaning image schemas in cognitive linguistics. Berlin/New York: Mouton de Gruyter.

Jamrozik, A., McQuire, M., Cardillo, E. R., \& Chatterjee, A. (2016). Metaphor: Bridging embodiment to abstraction. Psychonomic Bulletin \& Review, 23, 1080-1089.

Johnson, M. (1987). The body in the mind: The bodily basis of meaning, imagination, and reason. Chicago: The University of Chicago Press.

Kiefer, M., \& Pulvermüller, F. (2011). Conceptual representations in mind and brain: Theoretical developments, current evidence and future directions. Cortex, 48(7), 805-825.

Kövecses, Z. (2010). Metaphor: A practical introduction. Oxford: Oxford University Press.

Krzeszowski, T. P. (1993). The axiological parameter in preconceptual image schemata. In R. A. Geiger \& B. Rudzka-Ostyn (Eds.), Conceptualizations and mental processing in language. (pp. 307-329). Berlin/New York: Mouton de Gruyter.

Lakoff, G. (1987). Women, fire, and dangerous things: What categories reveal about the mind. Chicago: The University of Chicago Press.

Lakoff, G. (1990). The invariance hypothesis: Is abstract reason based on image-schemas? Cognitive Linguistics, 1(1), 39-74.

Lakoff, G. (1993). The contemporary theory of metaphor. In A. Ortony (Ed.), Metaphor and thought. (pp. 203-249). Cambridge: Cambridge University Press.

Lakoff, G., \& Johnson, M. (1980). Metaphors we live by. Chicago: University of Chicago Press.

Lakoff, G., \& Turner, M. (1989). More than cool reason: A field guide to poetic metaphor. Chicago: University of Chicago Press.

Lakoff, G., Swenson, J., \& Schwartz, A. (1991). Master metaphor list (2nd ed.). Technical report, University of California at Berkeley.

Lakoff, G., \& Johnson, M. (1999). Philosophy in the flesh: The embodied mind and its challenge to western thought. New York: Basic Books.

Langacker, R. W. (1987). Foundations of cognitive grammar, vol. 1: Theoretical prerequisites. Stanford: Stanford University Press.

Mandler, J. M. (1992). How to build a baby: ii. Conceptual primitives. Psychological Review, 99, 597-604.

Mandler, J. M., \& Cánovas, C. P. (2014). On defining image schemas. Language and Cognition, 6, 510-532.

Martin, A., \& Chao, L. L. (2001). Semantic memory and the brain: Structure and processes. Current Opinion in Neurobiology, 11, 194-201.

Moneglia, M. (2014a). Natural language ontology of action, a gap with huge consequences for natural language understanding and machine translation. In Z. Vetulani \& J. Mariani (Eds.), Human language technology challenges for computer science and linguistics (pp. 379-395). Berlin/New York: Springer.

Moneglia, M. (2014b). The semantic variation of action verbs in multilingual spontaneous speech corpora. In T. Raso \& H. Mello (Eds.), Spoken corpora and linguistics studies (pp. 152-190). Amsterdam: John Benjamins.

Moneglia, M., Monachini, M., Calabrese, O., Panunzi, A., Frontini, F., Gagliardi, G., \& Russo, I. (2012). The IMAGACT cross-linguistic ontology of action. A new infrastructure for natural language disambiguation. In N. Calzolari, K. Choukri, T. Declerck, M. Uğur Doğan, B. Maegaard, J. Mariani, J. Odijk \& S. Piperidis (Eds.), Proceedings of the Eight International Conference on Language Resources and Evaluation (pp. 948-955). Paris: European Language Resources Association (ELRA).

Panunzi, A., \& Moneglia, M. (2004). La Variazione Primaria del verbo nel lessico dei corpora di parlato. In F. Albano Leoni, F. Cutugno, M. Pettorino \& R. Savy (Eds.), Atti del Convegno Il Parlato Italiano, volume CD-ROM, C4 (pp. 1-24). Napoli: D’Aura Edizioni. 
Panunzi, A., \& Vernillo, P. (2019). Metaphor in action. Action verbs and abstract meaning. In M. Bolognesi \& G. J. Steen (Eds.), Perspectives on abstract concepts. Cognition, language and communication (pp. 215-237). Amsterdam: John Benjamins.

Panunzi, A., De Felice, I., Gregori, L., Jacoviello, S., Monachini, M., Moneglia, M., \& Quochi, V. (2014). Translating action verbs using a dictionary of images: The IMAGACT ontology. In A. Abel, C. Vettori \& N. Ralli (Eds.), Proceedings of the XVI EURALEX International Congress: The User in Focus (pp. 1163-1170). Bolzano: EURAC Research.

Pulvermüller, F. (2005). Brain mechanisms linking language and action. Nature Reviews Neuroscience, 6, 576-582.

Rohrer, T. (2006). Image schemata in the brain. In B. Hampe (Ed.), From perception to meaning: Image schemas in cognitive linguistics (pp. 165-196). Berlin: Mouton de Gruyter.

Rudzka-Ostyn, B. (1995). Metaphor, schema, invariance: The case of verbs of answering. In L. Goossens, P. Pauwels, B. Rudzka-Ostyn, J. Vanparys \& A. M. Simon-Vandenbergen (Eds.), By word of mouth: Metaphor, metonymy and linguistic action in a cognitive perspective: Studies in meaning extension in linguistic action. (Pragmatics and beyond) (pp. 206-244). Amsterdam/Philadelphia: John Benjamins.

Talmy, L. (1983). How language structures space. In H. L. Pick \& L. P. Acredolo (Eds.), Spatial orientation: Theory, research, and application (pp. 225-282). New York/London: Plenum Press.

Talmy, L. (2000). Toward a cognitive semantics. Cambridge, MA: MIT Press.

Tettamanti, M., et al. (2005). Listening to action-related sentences activates fronto-parietal motor circuits. Journal of Cognitive Neuroscience, 17(2), 273-281.

Tomasello, M. (2003). Constructing a language. Cambridge, MA: Harvard University Press.

Turner, M. (1991). Reading minds: The study of English in the age of cognitive science. Princeton, NJ: Princeton University Press.

Varela, F. J., et al. (1991). The embodied mind: Cognitive science and human experience. Cambridge, MA: MIT Press.

Vernillo, P. (2019). The role of the image Schemas in the analysis of the semantic variation of action verbs. Data from IMAGACT. In O. Kutz \& M. Hedblom (Eds.), Tricolore 2018. Creativitycognition-computation. Bozen-Bolzano, 13-15 December 2018.

Wilson, M. (2002). Six views of embodied cognition. Psychonomic Bulletin \& Review, 9, 625-636.

Zipoli Caiani, S. (2011). The embodied theory of language: Evidence and constrains. Logic and Philosophy of Science, 9(1), 485-491.

Open Access This chapter is licensed under the terms of the Creative Commons Attribution 4.0 International License (http://creativecommons.org/licenses/by/4.0/), which permits use, sharing, adaptation, distribution and reproduction in any medium or format, as long as you give appropriate credit to the original author(s) and the source, provide a link to the Creative Commons license and indicate if changes were made.

The images or other third party material in this chapter are included in the chapter's Creative Commons license, unless indicated otherwise in a credit line to the material. If material is not included in the chapter's Creative Commons license and your intended use is not permitted by statutory regulation or exceeds the permitted use, you will need to obtain permission directly from the copyright holder.

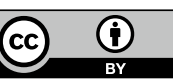

